\title{
Efficiency, productivity and targets: The gap between ideology and reality in the call centre
}

\author{
Anthony Lloyd, Teesside University, UK
}

\begin{abstract}
This paper draws upon data from an ethnographic study of a UK call centre to investigate the claims of efficiency and productivity that underpin service occupations. Neoliberal ideology valorises competition, profitability and the free market, imperatives which filter down to organisational level and manifest as the pursuit of efficiency. The evidence in this paper highlights how the call centre's quest for efficiency is undermined by inefficiencies that are inherent in management implementation of work routines designed to maximise efficiency. While management practice and automated work routines may not be efficient, they do generate specific outcomes; the oppression, abuse and domination of employees both in relation to conditions of employment and working conditions.
\end{abstract}

Keywords - sociology, efficiency, targets, neoliberalism, ideology, call centres, managerialism, exploitation

\section{Introduction}

The original contribution of this paper is to critically analyse the concept of 'efficiency' in relation to organisational practice. The call centre purports to offer an 'efficient' delivery system for customer care, a consolidation of services into one interface of telecommunications and information technology, facilitated by the Customer Service Representative (Woodcock, 2017; Taylor and Bain, 1999). However, through evidence presented from an ethnographic study of a call centre in the North East of England, this paper suggests that the implementation of market ideology at the level of managerial practice fails to provide the intended outcomes. More problematically, the managerialist ethos of efficiency and productivity, backed by performance management and target-driven processes, invites an approach to employee relations that results in particularly problematic and degrading forms of exploitation and control. 
Firstly, the paper will outline the imperatives of market ideology and its subsequent retooling of management strategy to highlight the quest for efficiency at an organisational level. Secondly, the paper will outline the methodology and the case study that underpins this paper. Thirdly, findings from this study will demonstrate what management drivers for productivity and efficiency do and do not accomplish. The pursuit of efficiency engenders inherently inefficient practice and simultaneously facilitates abusive and harmful treatment of employees. The conclusion will address some of the issues related to ideological rhetoric and reality and how inefficient processes in the call centre relate to neoliberal politicaleconomic ideology. This paper utilises an analytical framework comprising the macro, meso and micro. Through discussion of the macro level of neoliberal political economy and ideology, the meso level context of organisational culture and management practice, and the micro level of individual action and experience, this paper elucidates the relationship between ideology and the subject.

\section{Market ideology and the neoliberal ideal}

Debate continues around the historical, epistemological and ontological foundations of neoliberalism (Foucault, 2008; Harvey, 2005; Mirowski, 2013). For Gane (2015), neoliberalism is a form of governance that 'seeks to inject market principles and competition into all aspects of society and culture'. Broadly speaking, it maintains an epistemological and ontological understanding of the human subject as rational actor who, through competition and the organising logic of the market, rejects conflict in favour of co-operation and mutual interest (Gane, 2015; Mirowski, 2013). This framework underpins the ideological roots of neoliberalism; a commitment to free markets, private property and competition best reflects human nature and provides the preeminent opportunity to maximise potential and growth (Harvey, 2005). Commitment to free market economics ebbed during the post-war social democratic consensus but re-emerged when economic crises in the early 1970s shook the foundations of Keynesian polity (Harvey, 2005). Neoliberal ideology entered the political mainstream in the 1980 s and fundamentally altered the social, economic and political landscape of the UK and elsewhere.

The post-war consensus was ultimately an aberration in the longue dureè of capitalism (Piketty, 2014); a brief interregnum of welfarist policy in a historical period underpinned by 
the tendency for the rate of return on capital investment to exceed overall economic growth, leading to profit accumulating amongst the already wealthy. Bobbitt (2002), on the other hand, identifies a clear shift in constitutional framework at the end of the $20^{\text {th }}$ century; the nation-state replaced by a market-state less inclined towards mass free public education, universal franchise and social security in favour of maximising opportunity, privatising public services and ensuring democratic procedures are less influential and more responsive to the market. In different ways, each suggests a shift in logic towards the end of the $20^{\text {th }}$ century that favours market forces and the imperatives of capital (Harvey, 2010). Streeck (2016) has indicated that the dynamic tension between capitalism and democracy has created a problematic contradiction whereby the market is prioritised over the public; the current 'consolidation state' (Streeck, 2016) of austerity (Stuckler and Basu, 2013) may generate harmful consequences for the UK's citizenry but is entirely in keeping with the need to service the market first.

The macro level of neoliberal market ideology travels down the slope of social structure and permeates managerial culture and organisational logic at the meso level (Lloyd, 2013). Organisational culture and management practice have been retooled in order to ensure the hegemonic logic of neoliberal market ideology is embedded in practice. This is visible in a wide array of examples including the criminal justice system (Whitehead, 2015), education, health care, the service economy (Ellis and Taylor, 2006), and manufacturing. The implementation of market ideology at the managerial meso level requires the adoption of a new set of practices and imperatives reflective of what Boltanski and Chiapello (2005) call the 'new spirit of capitalism'. For profitability to be realised at organisational level, managerialist philosophy has increasingly become concerned with efficiency, just-in-time delivery and lean workforces, overseen by targets and performance management (Lloyd, 2013, 2018; Whitehead, 2015; Taylor and Bain, 1999). In this context, the call centre is emblematic of the quest for efficiency and profitability (Kinnie et al, 2008); as such, the following section will explore the call centre literature in detail.

\section{What we know about call centres}

Call centre research principally focuses on organisational structure and management strategy along with the impact of work processes on employees. Deery and Kinnie (2002) classify call 
centre research into four categories (also Lloyd, 2016). Firstly, the characteristics and organisational composition (Taylor and Bain, 1999) of the workplace include a number of studies portraying call centres as low-paid, stressful working environments where a controlling system of technological and human monitoring limits autonomy (Bain and Taylor, 2002; Townsend, 2005). Attempts to identify 'call configurations' that differentiate ideal types of call centre (Glucksmann, 2004) indicate further similarities and differences. Skill levels are regularly contested; some argue call centres are relatively low-skilled (Lloyd and Payne, 2009) whilst others acknowledge the complexity of operations (Russell, 2008) or the requirement to use 'cognitive' (McFadden, 2015) or 'emotional' (Deery et al, 2002) labour.

Secondly, the choices and strategies of management emphasise quantity versus quality (Robinson and Morley, 2006) and workflows or management practices tied to the logic of productivity and realisation of targets (Bain et al, 2002; Kinnie et al, 2008). Research has identified 'scientific management' techniques of speed-up and control through technology (Deery et al, 2002), what Brown et al (2011) term 'digital Taylorism', as well as cultural control through recruitment of the 'right people' (Callaghan and Thompson, 2002; van den Broek, 2004). Fleming and Sturdy (2011) identify a control strategy encouraging workers to 'be yourself', creating a 'fun' environment which masks a controlling work process, whilst Brannan (2015) employs Bourdieu's concept of symbolic violence to elaborate on processes of domination and subordination linked to retention strategies.

Thirdly, call centre literature focuses on the effect of work, citing a catalogue of physical and psychical hardships (Deery et al, 2002; Holman, 2003; Wegge et al, 2010). These work processes are incongruous with good health and well-being (Taylor et al, 2003); employees suffer from physical problems associated with prolonged sitting, extended use of headsets and screens and the psychical problems associated with this kind of emotional labour (Hochschild, 2003). Finally, employee response has been a prominent avenue of research (Mulholland, 2004; Sarkar and Charlwood, 2014; Townsend, 2005). Literature focuses on resistance within the labour process and the role of unions within the sector, highlighting continuities with existing labour process theories to identify areas of solidarity and potential sites of resistance. However, call centre workers often know they are being exploited but continue to participate in the labour process anyway (Lloyd, 2017). This requires us to rethink 
the relationship between the subject and ideology before we can assert the presence of 'resistance'.

Much of the call centre literature fails to connect organisational practice, management attitude and employee well-being within a broader framework of politics and economics. There are some notable exceptions (Brophy, 2010; McFadden, 2015). Hill (2015) and Brophy (2010) place the call centre within the framework of 'communicative capitalism' (Dean, 2009). Call centre workers, programmers, financial traders, hospitality and service workers, carers and others draw upon cognitive potential to create value (Hill, 2015). This pulls one's subjectivity into the labour process in a way that often generates emotional and psychical exhaustion. However, much of the literature remains rooted in organisational structure, management practice and labour process. The call centre can act as a case study of neoliberalism's ideological and material impact on human subjects and organisational structures - a case study that meshes macro, meso and micro dimensions. If the prevailing ideology valorises profitability and competition, and management attempts to achieve this through targets, performance management and the pursuit of 'efficiency', we can investigate its impact in practice.

\section{Methodology}

Data were collected through covert participant observation in a call centre in North East England and interviews with co-workers and call centre workers. Sociology has a long tradition of utilising ethnography in the workplace (Beynon, 1973; Ho, 2009; Winlow, 2001). Ethnographic methods often draw criticism for offering macro-level conclusions based on micro- or meso-level empirical data. However, ethnography can connect the micro, meso and macro, across a range of fields and disciplines (Burawoy, 1998). Whilst some suggest that single-site studies should focus on, for example, the organizational context of an institution without raising questions about the nature of the labour process, ethnography can offer an extended case method (Burawoy, 1998) drawing on external factors, wider political and economic contexts. Within the critical realist tradition, identifying the empirical reality of a single site serves as a starting point; using the single site as a gateway to uncovering underlying structures and processes that shape socio-economic, political, ideological and subjective reality (see Bhaskar, 2010; Collier, 1994). Philosophically, the ethnographic 
method allows for the identification of the Hegelian 'concrete universal'; a kernel of truth or reality in a particular location or environment that provides an intellectual bridge to the universal or macro. Participant observation in this case allows us to look critically at how workplace discourse of efficiency, productivity and targets impact upon the reality of call centre life and connect to wider ideological belief in the market, growth, and competition.

The research aims of uncovering daily practice, organisational structures and logic, management strategy and culture, and employee attitudes were best achieved through participant observation. Covert research is, as Calvey (2008: 908) notes, 'neither an 'anything goes' nor a 'one size fits all' policy but what is appropriate in that setting'. As Fine and Shulman (2009) indicate, every job or organisation has practices, techniques and strategies for doing things that they will avoid showing to outsiders. Only insiders will learn how an organisation functions, so honesty about the true research purpose may preclude entry. As such, ethical clearance was obtained and the participant observation was conducted covertly. I applied for a job at Call Direct, and successfully negotiated processes of recruitment and training before spending six months as a Customer Service Representative (CSR) on the Internet Plus broadband contract.

The literature on covert research often focuses on ethical issues around informed consent (Cho and Trent, 2006; Zavisca, 2007). All social research exhibits a continuum of disclosure and concealment which is not to say that covert ethnography is exempt from questions of consent but does problematise the seeming binary options of 'honest' (overt) and 'deceptive' (covert) research (Herrara, 1999). The demand for informed consent before participation presupposes that the participant can be fully informed of the research aims and objectives, a proposition that is often unrealistic and, sometimes, prohibitive towards inclusion and recruitment of participants and their contribution to the study (Zavisca, 2007). More importantly, the ethical questions attached to social research take place in the field rather than the design phase of a project (Calvey, 2008). Ethics, in the broader sense of a moral responsibility for another and a commitment to prevent harm, should guide decision-making in the field. In this sense, in the field situated ethics are perhaps more realistic than attempts to 'design out' risk factors at the planning stage. At times, the exclusion of data was regarded 
as the right thing to do, based on a number of factors including context and a responsibility to individual participants.

Interview data with co-workers supplemented ethnographic data. I engaged around 70 employees in short discussions during field work, held informal discussions with around 30 employees and followed up with 15 semi-structured, recorded interviews. These interviews included full disclosure of the research aims and objectives. Consent was recorded before interviews with clear guidelines about involvement in the study and rights to withdraw consent at any time after the interview. The ethnography positively facilitated the interview process; co-workers knew I had done the job, had been subject to seemingly arbitrary decisions from managers, had been shouted at by irate customers, and could empathise with what might, to an outsider, seem like a trivial matter that held great significance for the employee. Furthermore, the interviews served to substantiate the ethnographic detail. As a full participant in the call centre, engaged in the job, at times my role blurred between 'present' and 'observant', as well as 'passive' and 'active' (Fine and Shuman, 2009). Events, conversations and experiences written up in field notes could be interpreted subjectively therefore interviews served to corroborate and challenge my field notes and knowledge of the research location. Informants were aged between 18 and 30, split evenly across gender lines and were a mix of British White and British Asian. All worked full time for the National Minimum Wage and are anonymised here (as are Call Direct and Internet Plus).

\section{Managerial strategy and the pursuit of efficiency}

Call Direct is an outsourced call centre operation. With several hundred employees across two sites, Call Direct provides facilities and staff to a range of clients who contract out their customer service and technical support functions (Lloyd, 2013). The main site in this study had a number of floors, each devoted to a different client. Employees worked exclusively for one client. Call Direct provided services for a mobile phone operator, two broadband clients and a TV subscription provider. Each contract came with specific demands; Call Direct agreed to satisfy those demands and manage the overflow from the client's own in-house customer service operation. Rather than bearing the infrastructure and labour costs, companies outsource call centre operations to providers such as Call Direct to ensure short-term efficiency (Kinnie et al, 2008). In this study, Call Direct 'sold' its infrastructure, services and 
manpower to Internet Plus, a broadband provider, by guaranteeing the resources and capability to manage Internet Plus's customer service and technical support requirements.

This configuration is not uniform across a differentiated call centre sector (Glucksmann, 2004). Third-party providers engage in a highly competitive market and win contracts by appearing to guarantee anything the host company requires. The logic of neoliberalism centres around profitability and competition and at a managerial level, this manifests as the pursuit of efficiency and productivity. Call Direct competes with other outsource call centres but the 'coercive laws of competition' (Marx, 1990 [1867]) require it remains profitable or fails within an aggressively competitive marketplace. The managerial push for efficiency and productivity, or at least the offer of efficiency and productivity to lure clients, was clear in principle but in practice drove a set of behaviours that caused problems for Call Direct. Throughout the participant observation, low-level staff discontent was obvious on an almost permanent basis but occasionally flared up. This usually happened when shift changes were announced at short notice. Tracy was a HR manager at Call Direct, responsible for mapping shift patterns based on client demand,

"Because it's an outsource, it tends to be a lot of overspill from the main call centre, so they give you an estimate of the calls that are expected and they'll tell you when you're likely to receive them that day. Then you have to try and map that and say how many staff do we need available to do it."

"We were very much driven by what the client would give you in terms of the calls they would give you, you couldn't say, 'well, I'm sorry, I can't staff at that time of the day', they would say, 'that's your problem, that's what you're paid for'. That often meant that we were giving, I'd say probably, sometimes unreasonable shifts to staff, we were asking them to compensate for the poor call flow, but it was expected because it is an outsourced call centre, they would tend to say, 'we'll bend over backwards for whatever the client wants."

Tracy suggested that staff discontent often stemmed from an imperative to satisfy client's needs at any cost. Employees suffered because shifts changed at short notice. CSRs were 
frequently overworked because Call Direct often guaranteed management of greater call flow than staff capacity could successfully discharge. The competitive market for outsourced call centres meant guaranteeing efficiency. Tracy suggested,

\begin{abstract}
"Put some proper processes in place, start to treat the people better, have more thought for the fact people have to plan their lives, and that has to be down to the negotiations with the client, they shouldn't just bend over, their staff wouldn't put up with it so why should anybody else? There has to be reasonable discussions up front, not just saying yes we'll deliver what you want and trying to work out whether it's actually possible or not."
\end{abstract}

\begin{abstract}
"I think they've gone through phases where they've tried to do things the right way then another contract has come along which has forced them to do things very quickly and they've slipped back into their old practices, instead of being consistent saying 'this is how we want to do things, no matter what', they just end up cutting corners."
\end{abstract}

Outsourced call centres like Call Direct must ruthlessly pursue efficiencies to remain viable in a competitive market (Harvey, 2005), an imposition that adversely affects employees. Fearful of losing lucrative contracts, outsourced call centres often promise the world and worry about delivery afterwards. Changing shift patterns at short notice, restructuring teams, and demanding higher productivity are inevitable by-products of the quest to remain competitive. However, the practices Tracy describes seem to indicate a lack of efficient management; it appears contingent and flexible, often pursued under duress and without strategic intent.

Targets have become the master-signifier of efficiency within managerialist manifestations of neoliberal polity (Whitehead, 2015). The pursuit of efficient practice and increased productivity can be measured statistically and used to performance manage employees to ensure they meet demand. Call centre management strategy focuses upon productivity and overwhelmingly uses targets as the measure of this success (Bain et al, 2002). This has specific implications for work routines on the call centre floor. CSRs at Call Direct were aware of targets; average handling times for calls, number of calls taken, and percentage of time spent 
in wrap [finished a call but writing notes on the customer's account] or idle [signed in but not available]. Statistics were displayed around the call centre; white boards were placed next to each 'pod', a large oval table comprising twelve individual workstations, with handling times exceeding the average written in red ink for visible scrutiny. Seeing red figures next to one's name, knowing everybody else could see it, generated anxiety and embarrassment. When call volume rose, team leaders were expected to pressurise staff; if the percentage of customers who hung up before speaking to a CSR exceeded an arbitrary target, it reflected badly on Call Direct. Pressure mounted and many CSRs reported growing tension.

This generates an inevitable outcome; CSRs cut corners to satisfy demand for quick 'wrap up' by putting 'one-liners', a single line of information, on a customer's account. Typically, notes written on an account should be detailed, including a summary and resolution allowing the next CSR dealing with a query to pick up the story quickly. Numerous contacts indicated that sometimes CSRs would write nothing. This increased stress and frustration as customers had to recount details of previous calls in order for a CSR to catch up. During busy periods, CSRs did not have time to listen to a long summary; team leaders were pressuring them to 'wrap up'. The customer often reacts negatively when asked to recapitulate previous conversations, particularly if an issue remained unresolved. This commonly resulted in an angry call, further raising stress and pressure on the CSR. The drive for efficiency, the management practice of pushing CSRs to wrap up quickly led some to cut corners which served to redirect or delay rather than resolve problems.

Repetition is crucial to the work process (Mulholland, 2004). The division of labour ensures CSRs repeatedly dealt with the same type of call. In dealing with billing queries all day, autonomy is emphatically reduced. It becomes second nature to ask the right questions in the right place, use the correct scripted 'open' and 'close'. The comparison between the assembly-line of industrial modernity (Beynon, 1973) and the 'assembly line in the head' (Taylor and Bain, 1999) is clear. Repetition and division of labour also generate inherently inefficient processes and practices. Customers connected to the wrong department wait on hold while they are transferred or told to ring back and select a different menu option. Rather than receiving efficient service, customers become increasingly frustrated at being passed around. One evening in Customer Support, my team was quiet and our team leader was busy 
elsewhere. Technical Support calls were routed to our team but, lacking technical support training and enjoying the quiet shift, the first CSRs to take these calls became unhelpful, telling the customer that they had 'somehow' come through to the wrong team and needed to ring back. Soon everyone was doing this. Rather than helping the customer, CSRs refused to engage. Better yet, the Average Handling Time went down as calls were resolved quickly; our statistics, at least, were seen to be efficient.

The business model embodying neoliberal tenets of efficiency, productivity and lean working often misaligned with the operational model employed by management; seeking to ensure productivity and efficiency resulted in practices that delivered the opposite effect (Vidal, 2009). Twin management strategies of targets linked to performance-related bonuses and electronic surveillance ensure that workers maintain high levels of work (although not necessarily high levels of productivity). In the above example, the electronic system recognised we were working but the human aspect of call centre management failed; without the team leader's scrutiny, work avoidance was possible whilst appearing to work efficiently. However, poorly performing CSRs faced the humiliation of seeing their statistics displayed for public scrutiny. Call Direct made little or no attempt to help struggling employees. Utilising a Taylorist 'scientific management' approach, the call centre sets the pace at a level some can achieve and then demands everybody fulfils that target. CSRs failing to perform will not survive.

For some teams, targets are incentivised. The Customer Care Team (cancellations department) received targets for the number of customers retained per week. Setting targets for retention meant Care Team agents would avoid dealing with customers where retention would be difficult. Excuses were made for not taking over calls. This was a reflection of management attitudes towards customer care and retention. Call Direct and Internet Plus believed that customer cancellation reflects poorly on the CSR, shifting responsibility from the company to the individual. Internet Plus believed it reasonable that Ben, a pragmatic Care Team agent, 'saves' $60 \%$ of customers each week. When successful, Ben's team were rewarded with high-street vouchers. This guaranteed a consumer experience whilst existing outside the pay structure; Call Direct rewarded staff without paying more or reducing targets. Sally's team answered email enquiries and, upon hitting their target, were 'rewarded' with a 
$40 \%$ increase in their target. Stagnating wages over the last forty years, coupled with increased productivity, have served to work the employee harder without commensurate remuneration (Harvey, 2010). High-street vouchers serve as incentives to work harder without guaranteed reward. Only those capable of hitting targets are rewarded; work becomes a field of competition whereby weak and underperforming staff are criticised, humiliated and fired whilst the 'successful' climb over the bodies of exhausted co-workers and dissatisfied customers to win a guaranteed shopping experience. Embedded consumerism is central to contemporary society and our psycho-social make-up (Raymen and Smith, 2016); employees compete for high-street vouchers as a reward for meeting targets. Co-workers become pitched against each other, not a source of collective strength and support (Lloyd, 2017). It also encourages the 'wrong' behaviours, as Tracy points out,

\footnotetext{
"Because there's so much emphasis on targets, it drives the wrong behaviours. If you know you're going to be picked up on your targets, you'd find a way to make up your targets whether that gives quality service to the customer or not."
}

Cutting corners and sacrificing quality becomes 'normal'; as long as CSRs demonstrate good statistics they will be rewarded or, at least, not punished. When management valorise targets as the embodiment of efficiency and productivity, employees will 'shadow box' with the data (Winiecki, 2004) in order to present an artificial overview often bearing little resemblance to reality and masking the stress, pressure and effort behind achieving an arbitrary level of performativity. The capricious nature of targets drives the wrong behaviours, the quest for efficiency disregards quality which engenders a division of labour that often generates inefficient service; customers are passed around, told to ring back and CSRs fail to update customer accounts, ensuring further inefficiencies in future.

As organisations implement managerial strategies to succeed in competitive markets, efficiency and productivity, measured through targets and performance management, frequently become the standard approach. At Call Direct, the evidence suggested that routine and practice aimed at the generation of efficiency had a number of consequences that actively impeded its ability to achieve efficient and productive practice. However, this 
managerial approach also had intentional and unintentional negative consequences for employees. This is the subject of the following section.

\section{Managerial strategy and the accomplishment of harm}

If the evidence above indicates what the managerialist interpretation of ideological tenets fails to achieve i.e. efficiency, this section will focus on what it does achieve. The adoption of market ideology, in the form of efficiency and productivity, is a guise to mask the increase in abusive and degrading forms of exploitation and control. This exists on two fronts: the conditions of employment and the working conditions experienced on the call centre floor. The need for efficiency and productivity, epitomised by 'lean' workforces, serves as a rhetorical mask that barely disguises the desire to do the minimum; to implement temporary, fixed-term, zero-hour contracts, pay the minimum wage, and strip out employment rights and protections. As discussed above, the call centre literature has already demonstrated effectively the range of harms, abuses and exploitations involved in both the conditions of employment and the labour process. This section will not cover old ground but instead point to a number of examples from this study that identify the problematic aspects of call centre work orientated around the need for productivity.

All Call Direct employees assigned to Internet Plus had permanent contracts. No temporary or zero-hour contracts were used and recruitment agencies did not supply Call Direct with labour. However, despite this apparent stability, the balance of power in employment relations rested entirely with the company. Every new recruit was technically under a period of probation, officially six months long but in practice a much more malleable deadline. During this probationary period, significant leeway existed for the company to terminate contracts for those CSRs they felt did not fit or were deemed to be underperformers. The probation ended after a formal meeting with a line manager to review performance, targets and call monitoring statistics. Those deemed to be acceptable were formally retained; once statutory benefits such as sick pay now became incorporated into one's contract. For those who were regarded as poor performers, the probationary review signalled their immediate termination. 
All CSRs were informed of the intention to conduct a probationary review after six months but during the project, some CSRs with eight or nine months experience acknowledged that they still had not received their probationary review and so were still technically 'on trial'. The ability to withhold this review and, consequently, withhold benefits from employees, gave the company leverage over its workers. Whilst 'good' employees saw their probationary review postponed or ignored, 'problematic' employees routinely saw their probationary review brought forward, a universal signal to all that the employee would be fired that day. In the six months of observation for this project, four of my team members had probationary reviews brought forward and each was promptly fired. The company policy stated that major infractions were punishable by immediate termination whilst an accumulation of three minor infractions could also trigger dismissal.

Minor infractions were doled out by team leaders for a wide variety of infringements such as lateness, leaving one's terminal without logging the right code on the system, looking at external websites on work computers and general behaviour on the call centre floor. The imposition of these infractions often depended upon the team leader and the CSR involved and was thus an arbitrary application of company policy. One CSR, Ollie, was 19 , incredibly naive, impulsive and routinely drew attention to his behaviour at work. He had been saved by his team leader early in his employment after being caught 'dropping calls', hanging up on customers to avoid dealing with their enquiries. However, after five months at Call Direct his anger at a management decision to reject an annual leave request and his determination to fix it immediately saw him accrue three minor infractions in under an hour. His previous team leader had been newly appointed and keen to show her ability to manage troublesome staff so had fought to keep Ollie as she thought she could mould him into a model employee. His new team leader had no such intention. Ollie's behaviour had drawn the attention of the floor managers so his probationary review was arranged and he was sacked. These examples demonstrate how contractual status and the conditions of employment place the employee in a position of weakness. Their 'probationary' period coupled with the list of minor infractions that could trigger dismissal ensured that CSRs were insecure and precarious.

These conditions of employment inform the working conditions under which CSRs labour. Some call centres actively incorporate high turnover into management strategy (Wallace et 
al, 2000). Call Direct epitomised this trend towards a 'sacrificial' HR strategy that demanded high productivity and high targets without concern for employee well-being; staff are disposable, allowed to burn out quickly and leave, easily replaced by new recruits from stagnant local labour markets. On top of burnout, stress and humiliation, an employee without control over the pace of work is increasingly susceptible to alienation, particularly in forms of affective labour requiring the production and reproduction of emotion (Hochschild, 2003). CSRs were encouraged to 'smile down the 'phone'. One team leader remarked, "I know it sounds silly but try it; you really do feel in a better mood when talking to a customer if you're smiling." The requirement to 'perform' on every call was mentally exhausting; challenging forms of affective labour, coupled with pressure, tension and stress produced by targets and requirements to increase quality and quantity can enervate CSRs. Hitting targets reflects the imperative for profit maximisation. In an occupation where the performance of affective labour is essential in the drive for productivity, it is curious that prevailing management practices served to increase tension, pressure and humiliation on staff. Humiliation was packaged as motivation.

The ultimate example of dehumanising the employee in the name of productivity involved turning toilet breaks into a contested area between management and employees. The electronic system monitors statistics and performance; a CSR must enter a code into their 'Aspect' (the telephone-sized port connecting a CSR to the system) to account for their time. 'Idle' breaks were divided into numerous options; scheduled breaks, 'admin' to complete paperwork, 'one-to-one' for meeting a team leader, and a 'comfort break' for using the bathroom. The electronic system recorded how long each employee spent in the bathroom. At Call Direct, team leaders were required to account for their team's statistics and some were reproached for the number of 'comfort breaks' taken. Each CSR was to restrict daily use of comfort breaks to 19 minutes or less. Teams were criticised for the use of comfort breaks, adults were chastised for how long they spend in the toilet. One respondent, Liam, questioned this lack of autonomy,

\footnotetext{
“In terms of...the job you're doing, it is very structured as we've said, so it's almost like...you want some personal freedom which is when you want to go to the toilet, or whatever, or the time you take to do certain things. When that is
} 
micromanaged down it is basically taking away the last elements of personal freedom that you have."

The early shift $(7 \mathrm{am}-3.30 \mathrm{pm})$ at Call Direct had only one team on the floor. One morning we quickly had more than ten calls waiting leading to inevitable pressure to wrap up quickly and reduce the queue. One co-worker asked to use the bathroom, the team leader replied, "no, I'm sorry but there's too many calls waiting". The CSR remained seated and continued working. For young people engaged in insecure, flexible forms of affective labour in a locale with limited job opportunities, indignities are borne without question because there are few realistic alternatives. When the most basic human functions become a source of contention and CSRs are routinely denied permission to use the toilet, it highlights the level of micromanagement employed in the pursuit of productivity. Call Direct's management style of targets and monitoring made the bathroom a contested area, extending control to basic bodily functions; CSRs were denied permission to use the bathroom because, given the competitive nature of the market, the call centre worried more about hitting targets and retaining clients than the dignity of their staff.

Although this section has not substantively focused on issues and examples of labour process and control (see Lloyd, 2017) or monitoring and performance management (see Lloyd, 2013), it has identified a number of problematic outcomes for call centre employees. These outcomes stem from a managerial emphasis on productivity, flexibility and efficiency; employment contracts that allow the company to monitor and performance manage staff yet retain the ability to terminate those who underperform or fail to conform. The demand for emotional labour places strain on the employee expected to perform and invest one's own subjectivity into the labour process, for little reward or thanks. The use of targets to ensure profitability and efficiency drives a labour process and micro-management strategy that not only actively acknowledges and shrugs off the likelihood of burnout and turnover but prevents employees from performing essential bodily functions. The requirement for efficiency drives management practices that directly impact upon the physical and emotional well-being, dignity, and objective material existence of employees. The final section will discuss these findings and offer some conclusions. 


\section{Discussion}

This evidence presented above encourages a critical investigation of the pursuit of efficiency and productivity that characterises call centre management. If hegemonic ideology has a causative influence on culture and practice, then neoliberalism and its valorisation of profitability, competition and free markets directly impacts upon the managerial approach of organisations such as Call Direct. How successfully these ideological tenets translate into management practice and organisational culture is demonstrated through a series of examples that clearly indicate a failure to ensure efficient practice and the realisation of productivity. Managers cut corners to satisfy client demand, employees cut corners to ensure targets are achieved. Whilst performance indicators may represent the appearance of productivity and efficiency, the reality is quite different; CSRs find shortcuts to satisfy targets but in doing so kick problems down the road.

In some respects, this reflects Streeck's (2016) assertion that capitalism routinely fails to untangle its internal contradictions. Capitalism's contradictions have historically created problems that it must seek to surmount (Harvey, 2010). Rather than resolve the contradiction, capitalism's preferred method is to overcome the problem in a way that defers to a further future problem. The expansion of credit to households from the 1980 s onwards resolved the problem of economic stagnation and wage plateau of the 1970 s but created a future problem of reckless lending and indebtedness (Streeck, 2016). This contradiction came to a head with the 2007-08 financial crisis; its resolution through the 'consolidation state' of austerity merely postpones an inevitable future problem. On a micro level, the CSR will cut corners by leaving no note on the account and thus satisfies the immediate problem associated with performance and targets but inevitably postpones the ability to resolve the customer's issue as the next CSR to pick up the case is inadequately informed and disadvantaged in their attempt to help. The use of targets and performance management as a measure of efficiency inherently generates inefficient practice.

If efficiency and productivity measures are unsuccessful in achieving their intended outcomes it then becomes imperative to identify what they do achieve. This has been covered by the call centre literature for two decades and does not require repetition here. The key question is whether the imposition of managerial practice at organisational level is designed to achieve 
the ideological exhortation for profitability, success and competition, yet fails to achieve this in practice, or whether these imperatives and processes reflect other motivations. Fisher's account of 'capitalist realism' (2009) usefully allows us to consider the gap between ideology and practice. The neoliberal imperative embodied at organisational and managerial level as efficiency and productivity is unsuccessful in practice but is successful as an ideological disciplinary mechanism to control the employee.

The abuse, exploitation and humiliation foisted upon call centre workers in the name of productivity and efficiency is not the unintentional consequence of translational difficulties between political economic ideology and organisational practice and strategy. It is a deliberate attempt to discipline and control the employee. The narrative of efficiency and productivity provides an opportunity for management to squeeze profit from employees, control and monitor CSRs, speed up and automate work processes, and performance manage and turnover underperforming or burned out recruits. Fisher (2009) suggests that neoliberalism has invaded the social, personal and political psyche to convince us that there is no alternative to free market capitalism. In the absence of an alternative, all that remains is the careful and efficient administration of the status quo. The market, as the primary mechanism for social organisation under neoliberalism, pits organisations in direct competition and the profit motive at the heart of capitalism compels companies to seek any and all ways to ensure profitability. In this sense, 'efficiency' is about maximisation of resources in the pursuit of profit, not the pursuit of excellent customer service. The shift in power from labour to capital, facilitated by the state's protection of market functions (Harvey, $2005 ; 2010)$, leaves employees exposed to these iniquities. However, as individual freedom also lies at the heart of neoliberal ideology, a collective response to these conditions is negated (see Lloyd, 2017).

\section{Conclusion}

Within the call centre, work intensification, automated individualised labour processes, personal targets and performance management in the name of efficiency combine with precarious and insecure conditions of employment to implement a disciplinary form of control on the employee. The employee as a subject of ideology reproduces these restraints and controls by 'playing the game', working harder and faster, competing against co-workers 
for rewards and ensuring they can pay the bills at the end of the month. The call centre work process is inherently inefficient but is successful as a tool of disciplinary control as individual freedom, fuelled by competition and precarity, drives the employee down an avenue that accepts and reproduces a problematic work process.

As the evidence in this paper has demonstrated, the call centre operation invokes the spirit of efficiency, productivity and effectiveness in its managerial ethos and labour process. In reality, it fails to deliver efficiency or productivity as the process itself is flawed; for example, the use of targets ensures that employees jettison good practice in favour of satisfactory performance indicators. The quest for efficiency undoubtedly damages the oppressed call centre worker but it also ensures an environment where organisational practice, management strategies and conditions of employment prevent the worker from seeking redress or change. The wider ideological significance of capitalist realism lies in its insistence that there is no alternative. The worker with responsibilities cannot afford to rock the boat and challenge the management practices that creep in under the guise of 'efficiency'. Employees oppressed and abused in the name of efficiency may recognise this as self-evident but the true violence of neoliberalism convinces us that any alternative would be worse. 


\section{References}

Bain P et al (2002) 'Taylorism, targets and the pursuit of quantity and quality by call centre management' New Technology, Work and Employment, 17(3) 170-185.

Bain P and Taylor P (2002) 'Entrapped by the 'electronic panoptican'? Worker resistance in the call centre' New Technology, Work and Employment, 15(1) 2-18.

Beynon H (1973) Working for Ford, London: Penguin.

Bhaskar R (2010) Reclaiming Reality: A Critical Introduction to Contemporary Philosophy, London: Routledge.

Bobbitt P (2002) The Shield of Achilles: War, Peace and the Course of History, London: Penguin. Boltanski L and Chiapello E (2007) The New Spirit of Capitalism, London: Verso.

Brannan M (2015) 'You're not going anywhere': Employee retention, symbolic violence and the structuring of subordination in a UK-based call centre' The Sociological Review, 63(4) 801819.

Brophy E (2010) 'The subterranean stream: Communicative capitalism and call centre labour' Ephemera: Theory \& Politics in Organization, 10(3/4) 470-483.

Brown P, Lauder H and Ashton D (2011) The Global Auction, Oxford: University Press.

Burawoy M (1998) 'The Extended Case Method' Sociological Theory, 16(1) 4-33.

Callaghan G and Thompson P (2002) "We recruit attitude': The selection and shaping of routine call centre labour' Journal of Management Studies, 39(2) 233-254.

Calvey D (2008) 'The art and politics of covert research: Doing 'situated ethics' in the field' Sociology, 42(5) 905-918.

Cho J and Trent A (2006) 'Validity in qualitative research revisited' Qualitative Research, 6(3) 319-340.

Collier A (1994) Critical Realism: An Introduction to Roy Bhaskar's Philosophy, London: Verso. Dean J (2009) Democracy and Other Neoliberal Fantasies: Communicative Capitalism and Left Politics, London: Duke University Press.

Deery S and Kinnie N (2002) 'Call centres and beyond: A thematic evaluation' Human Resource Management Journal, 12(4) 3-13.

Deery S, Iverson R and Walsh J (2002) 'Work relationships in telephone call centres: Understanding emotional exhaustion and employee withdrawal' Journal of Management Studies, 39(4) 471-496. 
Ellis V and Taylor P (2006) “You don't know what you've got till it's gone': re-contextualising the origins, development and impact of the call centre' New Technology, Work and Employment, 21(2) 107-122.

Fine GA and Shuman D (2009) 'Lies from the field: Ethical issues in organizational ethnography' in Ybema S, Yanow D, Wels $\mathrm{H}$ and Kamsteeg FH (Eds) Organizational Ethnography: Studying the Complexity of Everyday Life, London: Sage.

Fisher M (2009) Capitalist Realism: There is No Alternative, Winchester: Zero.

Fleming P and Sturdy A (2011) "Being yourself' in the electronic sweatshop: New forms of normative control' Human Relations, 64(2) 177-200.

Foucault M (2008) The Birth of Biopolitics, Basingstoke: Palgrave.

Gane N (2015) 'Trajectories of Liberalism and Neoliberalism', Theory, Culture and Society, $32(1), 133-144$.

Glucksmann M (2004) 'Call configurations: Varieties of call centre and divisions of labour' Work, Employment and Society, 18(4) 795-811.

Harvey D (2005) A Brief History of Neoliberalism, Oxford: University Press.

Harvey D (2010) The Enigma of Capital, London: Profile.

Herrara CD (1999) 'Two arguments for 'covert methods' in social research' The British Journal of Sociology, 50(2) 331-343.

Hill D (2015) The Pathology of Communicative Capitalism, Basingstoke: Palgrave Pivot.

Ho K (2009) Liquidated: An Ethnography of Wall Street, London: Duke University Press.

Hochschild AR (2003) The Managed Heart: Commercialization of Human Feeling, London: University of California Press.

Holman D (2003) 'Phoning in Sick? An overview of employee stress in call centres' Leadership and Organization Development Journal, 24(3) 123-130.

Kinnie N, Purcell J and Adams M (2008) 'Explaining employees' experience of work in outsourced call centres' Journal of Industrial Relations, 50(2) 209-227.

Lloyd A (2013) Labour Markets and Identity on the Post-Industrial Assembly Line, Farnham: Ashgate.

Lloyd A (2016) 'Understanding the Post-Industrial Assembly Line: A Critical Appraisal of the Call Centre' Sociology Compass, 10(4) 284-293.

Lloyd A (2017) 'Ideology at Work: Reconsidering ideology, the labour process and workplace resistance' International Journal of Sociology and Social Policy, 37(5/6) 266-279. 
Lloyd A (2018) The Harms of Work: An Ultra-Realist Account of the Service Economy, Bristol: Policy Press.

Lloyd C And Payne J (2009) "Full of sound and fury, signifying nothing': Interrogating new skill concepts in service work - the view from two UK call centres' Work, Employment and Society, 23(4) 617-634.

Marx K (1990 [1867]) Capital. Vol. 1, Oxford: University Press.

McFadden P (2015) 'The Production of Politics in Front-Line Service Work: "Body Work" in the Labour Process of the Call Centre Worker' Global Society, 29(1) 89-106.

Mirowski P (2013) Never Let a Serious Crisis Go To Waste, London: Verso.

Mulholland K (2004) 'Workplace resistance in an Irish call centre: slammin', scammin', smokin', an' leavin" Work, Employment and Society, 18(4) 709-724.

Piketty T (2014) Capital in the Twenty-First Century, London: Belknap.

Raymen T and Smith O (2016) 'What's deviance got to do with it? Black Friday sales, violence and hyper-conformity', The British Journal of Criminology, 56(2), 389-405.

Robinson G and Morley C (2006) 'Call centre management: Responsibilities and performance' International Journal of Service Industry Management, 17(3) 284-300.

Russell B (2008) 'Call centres: A decade of research' International Journal of Management Reviews, 10(3) 195-219.

Sarkar S and Charlwood A (2014) 'Do cultural differences explain differences in attitudes towards unions? Culture and attitudes towards unions among call centre workers in Britain and India' Industrial Relations Journal, 45(1) 56-76.

Streeck W (2016) How Will Capitalism End? London: Verso.

Stuckler D and Basu S (2013) The Body Economic: Why Austerity Kills, London: Allen Lane. Taylor P and Bain P (1999) “'An assembly line in the head': Work and employee relations in the call centre", Industrial Relations Journal, 30(2) 101-117.

Taylor, P et al (2003) "A unique working environment': Health, sickness and absence management in UK call centres' Work, Employment and Society, 17(3) 435-458.

Townsend K (2005) 'Electronic surveillance and cohesive teams: Room for resistance in an Australian call centre?' New Technology, Work and Employment, 20(1) 47-59.

Van den Broek D (2004) "We have the values': Customers, control and corporate ideology in call centre operations' New Technology, Work and Employment, 19(1) 2-13. 
Vidal M (2009) ‘Routine inefficiency: Operational satisficing and real world markets’ in Bandelj N (Ed.) Economic Sociology of Work, Emerald Group Publishing Limited.

Wallace CM, Eagleson G and Waldersee R (2000) 'The sacrificial HR strategy in call centers' International Journal of Service Industry Management, 11(2) 174-184.

Wegge J, van Dick R and von Bernstorff C (2010) 'Emotional dissonance in call centre work' Journal of Managerial Psychology, 25(6) 596-619.

Whitehead P (2015) 'Payment by results: the materialist reconstruction of criminal justice' International Journal of Sociology and Social Policy, 35(5/6) 290-305.

Winlow S (2001) Badfellas: Crime, Tradition and New Masculinities, Oxford: Berg.

Woodcock J (2017) Working the Phones: Control and Resistance in Call Centres, London: Pluto Press.

Zavisca J (2007) 'Ethics in ethnographic fieldwork' Forum for Anthropology and Culture, 4 127146.

For correspondence: Anthony Lloyd, School of Social Sciences, Humanities \& Law, Teesside University, Clarendon Building, Middlesbrough, TS5 8UH, UK. Email: Anthony.Lloyd@tees.ac.uk 